\title{
Characterization of patients with hepatocellular carcinoma on the way for early detection: one center experience Salah Elgamal ${ }^{\mathrm{a}}$, Ahmed A. Ghafar ${ }^{\mathrm{a}}$, Elsayed Ghoneem ${ }^{\mathrm{a}}$, Moustafa Elshaer ${ }^{\mathrm{b}}$, Hani Alrefai ${ }^{\mathrm{b}}$, Wafaa Elemshaty ${ }^{\mathrm{c}}$
}

\author{
Departments of anternal Medicine, \\ bMicrobiology, Specialized Medical Hospital, \\ ${ }^{\circ}$ Clinical Pathology, Faculty of Medicine, \\ Mansoura University, Mansoura, Egypt \\ Correspondence to Ahmed A. Ghafar, \\ Department of Microbiology, Internal Medicine, \\ Hepatology and Gastroentrology, Specialized \\ Medical Hospital, Mansoura University, \\ Mansoura, Egypt. Tel: 01003958489; \\ e-mail: drahmedsaleh1981@gmail.com \\ Received 26 April 2018 \\ Accepted 9 July 2018 \\ The Egyptian Journal of Internal Medicine \\ 2018, 30:231-238
}

\begin{abstract}
Background
Hepatocellular carcinoma (HCC) is the commonest primary liver neoplasm that usually develop in the background of cirrhosis. Hepatitis $C$ virus is endemic in Egypt and is the major cause of cirrhosis. Studying the characteristics of patients with $\mathrm{HCC}$ may help in clarifying the schedule for screening of high-risk patients for an early detection of HCC.

\section{Patients and methods}

The 492 patients attending the hepatology and HCC clinics in Specialized Medical Hospital, Mansoura University for follow up of liver cirrhois and HCC were subjected to full history, physical examination, laboratory profile, and imaging studies needed for the diagnosis. Data were collected and analyzed. According to the radiological results, patients were divided into three groups (fibrosis, cirrhosis, and HCC) and compared.

Results

The study included 336 males and 156 females. Patients with HCC were mainly males with a mean age of 58 years. A statistically significant difference between $\mathrm{HCC}$ group and the other groups with respect to hemoglobin level, white blood cells count, platelet count, aspartate aminotransferase, alanine aminotransferase, albumen level, serum bilirubin, international normalized ratio, and $\alpha$-fetoprotein (AFP) was found. The sensitivity and specificity of AFP in differentiating HCC cases are 81.1 and $71.9 \%$, respectively. Logistic regression for prediction of HCC showed that males with age greater than 58 years, hypoalbuminaemia, and AFP greater than $11.2 \mathrm{ng} / \mathrm{dl}$ have a $76.3 \%$ positive predicted value.

\section{Conclusion}

Cirrhotic patients with age greater than 58 years, males, hypoalbuminaemia, and AFP greater than $11.2 \mathrm{ng} / \mathrm{dl}$ are at a higher risk to develop HCC more than other patients and should be monitored at close quarters with better contrast-enhanced technique either contrast-enhanced ultrasound or computed tomography scan.
\end{abstract}

Keywords:

hepatocellular carcinoma

Egypt J Intern Med 30:231-238

(C) 2019 The Egyptian Journal of Internal Medicine

1110-7782

\section{Introduction}

Hepatocellular carcinoma ( $\mathrm{HCC}$ ) is the most common primary liver tumor and considered the third leading cause of cancer-related deaths in the developed countries [1]. Most of the HCC cases develop in the presence of cirrhosis related to viral hepatitis. In particular, hepatitis $\mathrm{C}$ virus $(\mathrm{HCV})$ and hepatitis $\mathrm{B}$ virus infections are considered as major risk factors for HCC worldwide. However, recent studies reported increasing number of HCC in NAFLD [2].

In Egypt, liver cancer constitute about $11.75 \%$ of all gastrointestinal tumors and $1.68 \%$ of total malignancies. Among Egyptians, HCC forms $70.48 \%$ of all liver tumors. HCC shows a growing incidence in Egypt as it represents the main complication of cirrhosis, related to chronic HCV infection. This may be because of the shift in the relative importance of $\mathrm{HCV}$ and hepatitis $\mathrm{B}$ virus as primary risk factors, and the improvements in diagnostic tools and screening programs [3].

HCC may grow silently in patients with good hepatic function and escape early detection due to vague presentation and nonspecific symptoms. This may be attributed to limited surveillance resources in developing countries. In contrast, a more deterioration in clinical symptoms may occur in patients with impaired liver functions. In advanced stages, the patient may present with vague right hypochondrial discomfort or pain, tender hepatomegaly, cholestatic jaundice, and pyrexia of an unknown origin. Nonspecific symptoms

This is an open access journal, and articles are distributed under the terms of the Creative Commons Attribution-NonCommercial-ShareAlike 4.0 License, which allows others to remix, tweak, and build upon the work non-commercially, as long as appropriate credit is given and the new creations are licensed under the identical terms. 
of advanced malignancy, such as poor appetite, nausea, and weight loss are less frequently found. Sudden liver decompensation may occur in patients with unrecognized cirrhosis or known compensated cirrhosis [4].

The diagnosis of HCC depends mainly on radiological studies as well as laboratory tests. The radiological techniques used in diagnosis, treatment planning, and follow up of HCC are ultrasonography (US), computed tomography (CT) scanning, and MRI [5].

$\alpha$-Fetoprotein (AFP) is the most frequently used serological marker for screening $\mathrm{HCC}$ in patients with liver cirrhosis. However, its sensitivity depends on the tumor size, where it is about $25 \%$ for lesions smaller than $3 \mathrm{~cm}$ and $50 \%$ for tumors larger than $3 \mathrm{~cm}$ in diameter. Other serum biomarkers and a new generation of immunoglobulin $\mathrm{M}$ immunocomplexes did not succeed in providing diagnostic accuracy. However, simultaneous assay of these markers in different combinations could improve sensitivity [6].

In this study, we tried to clarify the risk factors, clinical, laboratory, and radiological features of $\mathrm{HCC}$ for an early detection in order to optimize the therapy.

\section{Patients and methods \\ Patients}

This is a retrospective, descriptive, cross-sectional study that was conducted on 492 patients attending to Hepatology Clinics, Specialized Medical Hospital, Mansoura University, from January 2015 to January 2017 for follow up of liver cirrhosis and were suspected to have HCC. All patients were subjected to physical examination with special stress on the presence of signs of decompensation as ascites, jaundice, or tremors. In history taking, age, sex, residency, occupation, smoking or ex-smoker, presenting complaint, jaundice, itching, abdominal pain, weight loss, history of previous hepatic encephalopathy, history of previous antiviral treatment, history of previous bilharziasis or antibilharzial, treatment and presence of comorbidities, such as diabetes mellitus or hypertension were evaluated.

\section{Laboratory assessment}

Complete blood count, serum creatinine, liver function tests with Child-Pugh classification, hepatitis B virus surface antigen, $\mathrm{HCV} \mathrm{Ab}$, and $\mathrm{AFP}$ were done for all patients.

\section{Imaging studies}

Evaluation of all patients with abdominal ultrasound and contrast-enhanced computed tomography (CEUS) was done. Diagnosis of $\mathrm{HCC}$ is made on presence of nodular lesion with arterial enhancement in the arterial phase and rapid washout in the portal phase. According to American Association for the Study of Liver Disease, every suspicious lesion in high-risk patients with suggestive US findings for HCC was evaluated. Furthermore, by multidetector CT scan or dynamic MRI with contrast, lesions that have the typical characters of $\mathrm{HCC}$ were identified, and the diagnosis of $\mathrm{HCC}$ was confirmed. Biopsy is not necessary for the diagnosis of $\mathrm{HCC}$ in a nodule greater than $2 \mathrm{~cm}$ at initial diagnosis, and is compatible with HCC after one dynamic study. According to radiology results, patients were divided into three groups:

(1) Group 1: patients with liver fibrosis.

(2) Group 2: patients with liver cirrhosis.

(3) Group 3: patients with HCC.

The three groups were compared with respect to clinical, laboratory, and radiological features. Group 3 is classified into five stages according to Barcelona Clinic Liver Cancer (BCLC). The classification and the five stages were compared. Evaluation of the patient included assessment of site of the lesion, number, size, vascularity, state of the portal vein (diameter and presence of portal vein thrombosis), presence of cirrhosis or ascites, size of the spleen, and presence of metastases, or lymph node affection.

\section{Statistical analysis}

Data were entered and statistically analyzed using the statistical package for the social sciences (SPSS; SPSS Inc., Chicago, Illinois, USA) version 20. Qualitative data were described as numbers and percentages with $\chi^{2}$-test used for comparison and Fischer exact and Monte Carlo tests were used when more than $20 \%$ of cells had count less than 5. Quantitative data were described as median and range for nonparametric data or mean and SD for parametric data after testing normality by Kolmogorov-Smirnov test. Kruskal-Wallis test and Mann-Whitney tests were used for comparison between groups for (nonparametric variables). Oneway analysis of variance test and Student's $t$-test (for parametric ones). Binary stepwise logistic regression analysis was used for prediction of independent variables of HCC from control. Significant predictors in the bivariate analysis were entered into regression model using forward Wald method. Adjusted odds ratios and their 95\% confidence interval were calculated. Receiver operating characteristics curve for detection of validity and cut-off point of AFP in diagnosing HCC cases detect sensitivity at vertical axis and 1specificity at horizontal axis. $P$ value less than or equal 
to 0.05 was considered to be statistically significant. All tests were two-tailed.

\section{Ethics}

The approval by Mansoura Medical Ethics Committee of Faculty of Medicine was obtained and written consents from patients participated in the study or from their family were also obtained.

\section{Results}

The study included 492 patients, 336 men and 156 women. Liver fibrosis was found in 92 patients, liver cirrhosis was found in 104 of cases, and diagnosis of $\mathrm{HCC}$ was zeroed on to 296 patient. There is statistically significant difference in age and sex distribution between the three groups where HCC group is more expressed in males with older ages. In contrast, there was no difference with respect to residency or occupation (Table 1). The clinical features of the studied groups are shown in Table 2.

The laboratory results of the studied groups showed statistically significant difference between HCC group and the other groups with respect to hemoglobin level, white blood cells count, platelet count, aspartate aminotransferase (AST), alanine aminotransferase, albumen level, serum bilirubin, international normalized ratio, and AFP (Table 3). The distribution of patients with $\mathrm{HCC}$ according to

Table 1 Demographic characters of the studied groups

\begin{tabular}{|c|c|c|c|c|}
\hline & Fibrosis $(N=92)[n(\%)]$ & Cirrhosis $(N=104)[n(\%)]$ & $\operatorname{HCC}(N=296)[n(\%)]$ & Test of significance \\
\hline \multicolumn{5}{|l|}{ Age (years) } \\
\hline Mean \pm SD & $42.04 \pm 11.5^{a, b}$ & $54.21 \pm 6.4^{\mathrm{a}, \mathrm{c}}$ & $58.11 \pm 6.9^{\mathrm{b}, \mathrm{c}}$ & $F=72.07 P<0.001^{*}$ \\
\hline \multicolumn{5}{|l|}{ Sex } \\
\hline Male & $50(54.3)^{a}$ & $60(57.7)^{b}$ & $226(76.4)^{a, b}$ & $\chi^{2}=11.27 P=0.003^{*}$ \\
\hline Female & $42(45.7)$ & $44(42.3)$ & $70(23.6)$ & \\
\hline \multicolumn{5}{|l|}{ Residence } \\
\hline Rural & $84(91.3)$ & $100(98.0)$ & $278(93.9)$ & ${ }^{\mathrm{MC}} P=0.38$ \\
\hline Urban & $8(8.7)$ & $4(2.0)$ & $18(6.1)$ & \\
\hline \multicolumn{5}{|l|}{ Occupation } \\
\hline Not working & $30(32.6)^{a}$ & $22(21.2)^{b}$ & $6(25.0)^{\mathrm{ab}}$ & $\chi^{2}=37.2 P<0.001^{*}$ \\
\hline Manual worker & $40(43.5)$ & $52(50.0)$ & $138(46.6)$ & $\chi^{2}=0.42 P=0.81$ \\
\hline Employee & $0(0.0)^{a}$ & $2(1.9)^{b}$ & $34(11.5)^{a b}$ & ${ }^{\mathrm{MC}} P=0.008^{*}$ \\
\hline Healthcare worker & $22(23.9)$ & $28(26.9)$ & $50(16.9)$ & $\chi^{2}=2.8 P=0.24$ \\
\hline
\end{tabular}

$\mathrm{HCC}$, hepatocellular carcinoma; MC, Monte Carlo test. ${ }^{\mathrm{a}, \mathrm{b}}$ There is a statistical significance between a and b. ${ }^{\mathrm{a}, \mathrm{c}}$ There is a statistical significance between $a$ and $c .{ }^{b, c}$ There is a statistical significance between $b$ and $c .{ }^{\star} P$ value is significant.

Table 2 History and clinical characters of the studied groups

\begin{tabular}{|c|c|c|c|c|}
\hline & Fibrosis $(N=92)[n(\%)]$ & Cirrhosis $(N=104)[n(\%)]$ & $\operatorname{HCC}(N=296)[n(\%)]$ & Test of significance \\
\hline \multicolumn{5}{|l|}{ Smoking history } \\
\hline No & $58(63.0)$ & $76(74.5)$ & $196(66.7)$ & ${ }^{\mathrm{MC}} P=0.79$ \\
\hline Smoker & $30(32.6)$ & $22(21.6)$ & $86(29.3)$ & \\
\hline Ex-smoker & $4(4.3)$ & $4(3.9)$ & $12(4.1)$ & \\
\hline Diabetes & $0(0.0)^{a, b}$ & $34(33.3)^{\mathrm{a}, \mathrm{c}}$ & $78(26.5)^{\mathrm{b}, \mathrm{c}}$ & ${ }^{\mathrm{MC}} P<0.001^{*}$ \\
\hline Hypertension & $6(6.5)$ & $16(15.7)$ & $48(16.3)$ & $\chi^{2}=2.84 P=0.24$ \\
\hline Operation history & $40(44.4)$ & $58(58.0)$ & $160(54.1)$ & $\chi^{2}=1.89 P=0.39$ \\
\hline Anti-HCV treatment & $30(32.6)^{a}$ & $90(88.2)^{a, b}$ & $214(72.3)^{\mathrm{b}}$ & $\chi^{2}=6.23 P=0.01^{*}$ \\
\hline \multicolumn{5}{|l|}{ Antibilharial treatment } \\
\hline No & $58(63.0)^{a, b}$ & $20(19.6)^{a, c}$ & $56(18.9)^{\mathrm{b}, \mathrm{c}}$ & ${ }^{\mathrm{MC}} P<0.001^{*}$ \\
\hline Oral & $26(28.3)$ & $62(60.8)$ & $120(40.5)$ & \\
\hline Injection & $8(8.7)$ & $20(19.6)$ & $120(40.5)$ & \\
\hline $\begin{array}{l}\text { Performance median } \\
\text { (minimum-maximum) }\end{array}$ & $0.0(0.0-0.0)^{a, b}$ & $0.0(0.0-3.0)^{a}$ & $1.0(0.0-4.0)^{\mathrm{b}}$ & ${ }^{\mathrm{KW}} P<0.001^{*}$ \\
\hline \multicolumn{5}{|l|}{ Encephalopathy } \\
\hline No & $92(100.0)$ & $100(98.0)$ & $284(95.9)$ & ${ }^{\mathrm{MC}} P=0.72$ \\
\hline Mild & $0(0.0)$ & $2(2.0)$ & $10(3.4)$ & \\
\hline Severe & $0(0.0)$ & $0(0.0)$ & $2(0.7)$ & \\
\hline
\end{tabular}

HCC, hepatocellular carcinoma; HCV, hepatitis C virus; KW, Kruskal-Wallis test; MC, Monte Carlo test. ${ }^{\text {a,b }}$ There is a statistical significance between $a$ and $b .{ }^{a, c}$ There is a statistical significance between a and $c .{ }^{b, c}$ There is a statistical significance between $b$ and $c$. ${ }^{\star} P$ value is significant. 
Table 3 Laboratory results of the studied groups

\begin{tabular}{|c|c|c|c|c|}
\hline & Fibrosis $(N=92)$ & Cirrhosis $(N=104)$ & $\operatorname{HCC}(N=296)$ & Test of significance \\
\hline $\mathrm{Hb}(\mathrm{g} \%)$ & $13.3 \pm 1.7^{\mathrm{a}, \mathrm{b}}$ & $12.22 \pm 2.1^{\mathrm{a}}$ & $12.33 \pm 1.65^{\mathrm{b}}$ & $F=5.9 P=0.003^{*}$ \\
\hline WBCs & $5700^{\mathrm{a}, \mathrm{b}}(3600.0-11300.0)$ & $4300^{\mathrm{a}, \mathrm{c}}(1700.0-12280.0)$ & $5250^{\mathrm{b}, \mathrm{c}}(1900.0-170000.0)$ & ${ }^{\mathrm{kW}} P=0.003^{*}$ \\
\hline PLT & $\begin{array}{c}203000^{\mathrm{a}, \mathrm{b}} \\
(57000.0-347000.0)\end{array}$ & $\begin{array}{c}100000^{\mathrm{a}} \\
(35000.0-332000.0)\end{array}$ & $\begin{array}{c}105000^{\mathrm{b}} \\
(83.0-431000.0)\end{array}$ & ${ }^{\mathrm{kW}} P<0.001^{*}$ \\
\hline Serum creatinine (mg/dl) & $0.85 \pm 0.12$ & $0.91 \pm 0.24$ & $0.97 \pm 0.5$ & $F=1.3 P=0.27$ \\
\hline HCV PCR $\left(\times 10^{3}\right)$ & $450(1.666-12733.2)$ & $298(4.98-7520.0)$ & $302(0.0-2060473.7)$ & ${ }^{\mathrm{KW}} P=0.35$ \\
\hline ALT & $46.0(15.0-252.0)$ & $43.0^{\mathrm{a}}(10.0-147.0)$ & $56.0^{\mathrm{a}}(11.0-185.0)$ & ${ }^{\mathrm{kW}} P=0.048^{*}$ \\
\hline AST & $38.0^{\mathrm{a}, \mathrm{b}}(15.0-133.0)$ & $60.0^{\mathrm{a}}(12.0-199.0)$ & $67.5^{\mathrm{b}}(9.0-267.0)$ & ${ }^{\mathrm{KW}} P<0.001^{*}$ \\
\hline Serum albumin $(g / d l)$ & $4.38 \pm 0.46^{a, b}$ & $3.3 \pm 0.7^{\mathrm{a}}$ & $3.31 \pm 0.58^{\mathrm{b}}$ & $F=61.7 P<0.001^{*}$ \\
\hline Serum bilirubin $(\mathrm{mg} / \mathrm{dl})$ & $0.71^{\mathrm{a}, \mathrm{b}}(0.3-1.6)$ & $1.28^{\mathrm{a}}(0.4-9.1)$ & $1.3^{\mathrm{b}}(0.4-9.3)$ & $\mathrm{KW}_{P<0.001^{*}}$ \\
\hline INR & $1.07 \pm 0.1^{\mathrm{a}, \mathrm{b}}$ & $1.26 \pm 0.2^{\mathrm{a}, \mathrm{c}}$ & $1.25 \pm 0.2^{b, c}$ & $F=15.06 P<0.001^{*}$ \\
\hline AFP & $4.1^{\mathrm{a}, \mathrm{b}}(0.3-36.3)$ & $12.0^{\mathrm{a}, \mathrm{c}}(0.12-500.0)$ & $69.1^{\mathrm{b}, \mathrm{c}}(1.4-10400.0)$ & ${ }^{\mathrm{kW}} P<0.001^{*}$ \\
\hline
\end{tabular}

AFP, $\alpha$-fetoprotein; ALT, alanine aminotransferase; AST, aspartate aminotransferase; HCC, hepatocellular carcinoma; HCV, hepatitis C virus; INR, international normalized ratio; KW, Kruskal-Wallis test; MC, Monte Carlo test; PLT, platelets; WBC, white blood cells. ${ }^{a, b}$ There is a statistical significance between a and $b .{ }^{a, c}$ There is a statistical significance between a and $c .{ }^{b, c}$ There is a statistical significance between $\mathrm{b}$ and $\mathrm{c}$. ${ }^{*} P$ value is significant.

\section{Figure 1}

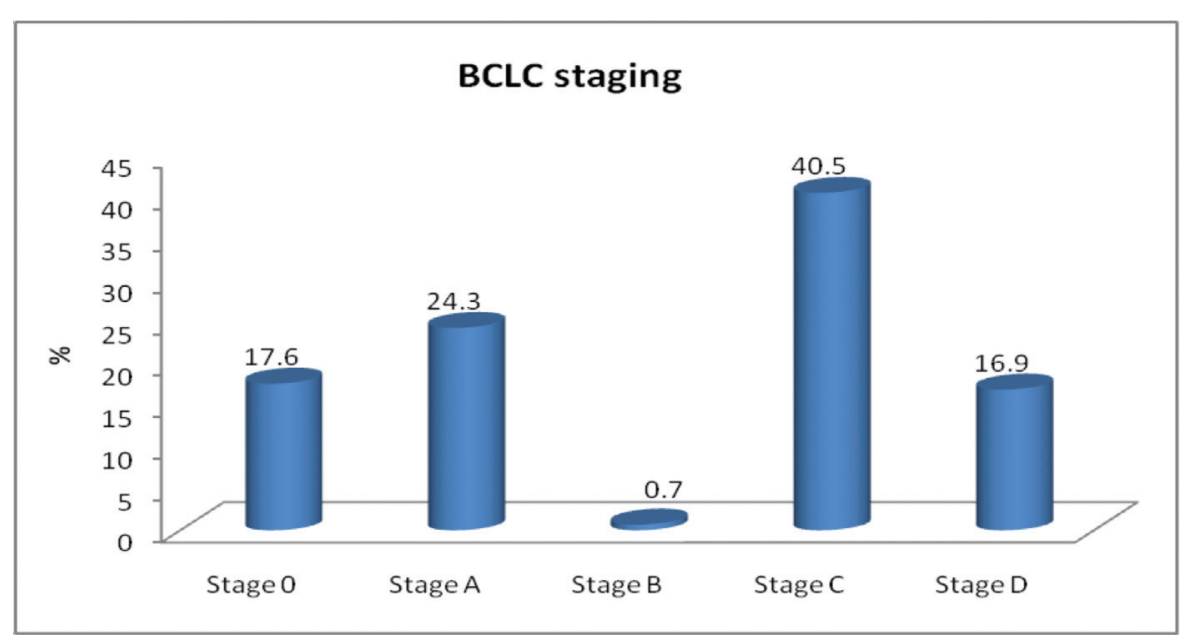

Distribution of studied hepatocellular carcinoma cases according to Barcelona Clinic Liver Cancer staging.

Table 4 Laboratory results of hepatocellular carcinoma cases according to the Barcelona Clinic Liver Cancer staging

\begin{tabular}{|c|c|c|c|c|c|c|}
\hline & Stage 0 & Stage A & Stage B & Stage C & Stage D & $\begin{array}{c}\text { Test of } \\
\text { significance }\end{array}$ \\
\hline $\mathrm{Hb}($ mean $\pm \mathrm{SD})$ & $12.38 \pm 1.3$ & $12.46 \pm 1.44$ & $12.9 \pm 0.0$ & $12.23 \pm 1.7$ & $12.33 \pm 2.1$ & $F=0.15 P=0.96$ \\
\hline Creatinine (mean $\pm S D$ ) & $0.91 \pm 0.23$ & $0.91 \pm 0.19$ & $0.6 \pm 0.0$ & $1.03 \pm 0.8$ & $1.01 \pm 0.4$ & $F=0.47 P=0.76$ \\
\hline Albumin $($ mean $\pm S D)$ & $3.74 \pm 0.35$ & $3.47 \pm 0.43$ & $4.2 \pm 0.0$ & $3.14 \pm 0.54$ & $2.98 \pm 0.7$ & $\begin{array}{c}F=9.93 \\
P<0.001^{*}\end{array}$ \\
\hline INR $($ mean $\pm S D)$ & $1.14 \pm 0.13$ & $1.23 \pm 0.25$ & $1.63 \pm 0.0$ & $1.28 \pm 0.2$ & $1.32 \pm 0.26$ & $F=3.2 P=0.013^{*}$ \\
\hline WBCs [median (range)] & $\begin{array}{c}5100 \\
(1900-7600)\end{array}$ & $\begin{array}{c}4965 \\
(2420-170000)\end{array}$ & $\begin{array}{c}3300 \\
(3300-3300)\end{array}$ & $\begin{array}{c}5350 \\
(2900-11000)\end{array}$ & $\begin{array}{c}5600 \\
(2700-15000)\end{array}$ & ${ }^{\mathrm{KW}} P=0.14$ \\
\hline PLT [median (range)] & $\begin{array}{c}116000 \\
(42000-182000)\end{array}$ & $\begin{array}{c}108000 \\
(6300-338000)\end{array}$ & $\begin{array}{c}37000 \\
(37000-37000)\end{array}$ & $\begin{array}{c}97500 \\
(83-431000)\end{array}$ & $\begin{array}{c}112000 \\
(57000-299000)\end{array}$ & ${ }^{\mathrm{KW}} P=0.08$ \\
\hline $\begin{array}{l}\text { HCV PCR }\left(\times 10^{3}\right) \\
\text { [median (range)] }\end{array}$ & $\begin{array}{c}114 \\
(0.0-4250)\end{array}$ & $\begin{array}{c}302 \\
(0.0-3760)\end{array}$ & $\begin{array}{c}0.0 \\
(0.0-0.0)\end{array}$ & $\begin{array}{c}291.48 \\
(0.0-3820)\end{array}$ & $\begin{array}{c}519.89 \\
(0.0-2060000)\end{array}$ & ${ }^{\mathrm{KW}} P=0.57$ \\
\hline ALT [median (range)] & $54.5(11-147)$ & $59(23-101)$ & $26(26-26)$ & $51.5(18-185)$ & $64(16-116)$ & ${ }^{\mathrm{KW}} P=0.46$ \\
\hline AST [median (range)] & $58.5(9-266)$ & $68(37-129)$ & $52(52-52)$ & $68(26-267)$ & $82(14-202)$ & ${ }^{\mathrm{kW}} P=0.23$ \\
\hline Bilirubin [median (range)] & $0.935(0.4-1.9)$ & $1.2(0.69-5)$ & $1.1(1.1-1.1)$ & $1.5(0.7-5.6)$ & $2.1(0.5-9.3)$ & ${ }^{\mathrm{kW}} P<0.001^{*}$ \\
\hline AFP [median (range)] & $\begin{array}{c}61 \\
(1.6-2532)\end{array}$ & $\begin{array}{c}64.8 \\
(1.4-7358)\end{array}$ & $\begin{array}{c}612 \\
(612-612)\end{array}$ & $\begin{array}{c}67.6 \\
(1.5-2379.9)\end{array}$ & $\begin{array}{c}500 \\
(4.7-10400)\end{array}$ & $\mathrm{kW}_{P=0.06}$ \\
\hline
\end{tabular}

ALT, alanine aminotransferase; AST, aspartate aminotransferase; Hb, hemoglobin; HCV, hepatitis C virus; INR, international normalized ratio; KW, Kruskal-Wallis test; PLT, platelets; WBC, white blood cells. ${ }^{*} P$ value is significant. 
BCLC staging is shown in Fig. 1. The laboratory characters of HCC stages according to BCLC staging is shown in Table 4 where there is no statistically significant difference between stages except for serum albumen and bilirubin. Table 5 assess the validity of US and CT in diagnosis of HCC. The sensitivity and specificity of AFP in differentiating $\mathrm{HCC}$ cases are shown in Fig. 2 and Table 6.

On logistic regression analysis of risk factors for prediction of $\mathrm{HCC}$ cases, it was found that age greater than 58 years, females, hypoalbuminaemia and AFP greater than 11.2 can predict $76.3 \%$ of HCC cases (Table 7).

\section{Discussion}

In Egypt, it is believed now that $\mathrm{HCC}$ is one of the common malignancies and a leading cause of death due to high prevalence of cirrhosis related to chronic $\mathrm{HCV}$.

Table 5 Ultrasonography and computed tomography validity in diagnosing hepatocellular carcinoma cases

\begin{tabular}{cccccc}
\hline & $\begin{array}{c}\text { Sensitivity } \\
(\%)\end{array}$ & $\begin{array}{c}\text { Specificity } \\
(\%)\end{array}$ & $\begin{array}{c}\text { Positive } \\
\text { predictive } \\
\text { value (\%) }\end{array}$ & $\begin{array}{c}\text { Negative } \\
\text { predictive } \\
\text { value (\%) }\end{array}$ & $\begin{array}{c}\text { Accuracy } \\
(\%)\end{array}$ \\
\hline US & 85.2 & 92.6 & 93.7 & 82.9 & 88.4 \\
CT & 99.3 & 83.9 & 96.7 & 96.3 & 96.6 \\
\hline
\end{tabular}

CT, computed tomography; US, ultrasonography.

Figure 2

ROC Curve for AFP in differentiating HCC

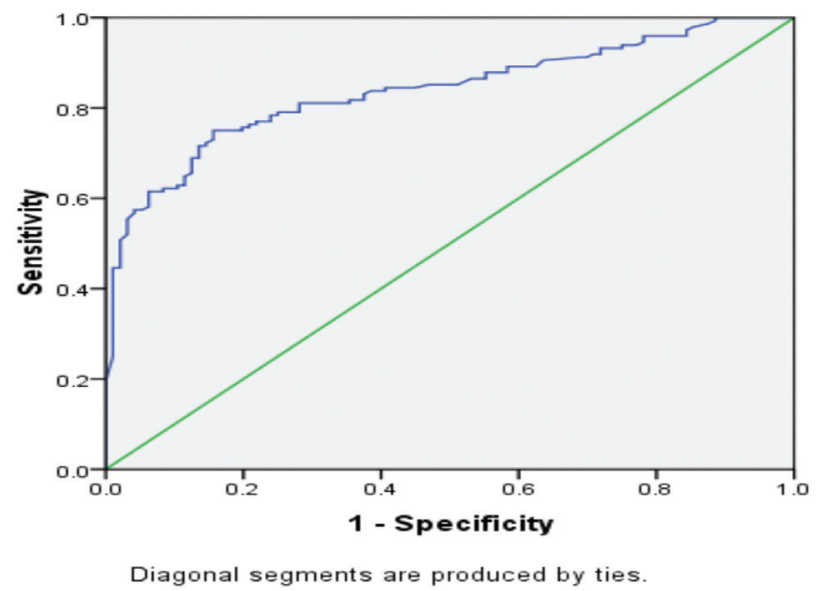

Sensitivity and specificity of $\alpha$-fetoprotein in differentiating hepatocellular carcinoma cases.
In previous years there is an increase in its incidence and it is expected that the number of cases continues to grow.

In our study, we found that $40.5 \%$ and $17.9 \%$ of HCC cases were diagnosed at stages $\mathrm{C}$ and $\mathrm{D}$ according to BCLC staging, respectively (Fig. 1). This is in contrast to a multicenter study in Spain where $49.8 \%$ of 705 cases with $\mathrm{HCC}$ were in the early stage A, $19.8 \%$ in intermediate stage $\mathrm{B}, 18.8 \%$ in advanced stage $\mathrm{C}$, and $11.6 \%$ in terminal stage $\mathrm{D}$ according to the BCLC classification [7]. This may be attributed to poor surveillance of our patients in addition to faults in US detection of small lesions because US is operator dependent. The limited treatment options available for these HCC stages emphasize the importance of detection of $\mathrm{HCC}$ cases at an early stage to maximize response to the therapy. This purpose starts from increasing awareness of our physicians about special characters of our patients with HCC attempting to clarify a more accurate schedule for surveillance of patients who are at increased risk of HCC.

The current study also showed that $76.4 \%$ of patients diagnosed with $\mathrm{HCC}$ were males with a mean age 58 years (Table 1). This is in agreement with many extensive studies as Carrilho et al. [8] who conducted a multicenter survey on 1405 patients with HCC over a 6-year period in Brazil, they found that males constitute $78 \%$ of their patients. Also, a study by Alves et al. [9] involving 210 patients with HCC reported that $83.3 \%$ of patients were men (76.6 and 83.3\%). GonÇAlves et al. [10] calculated a ratio of $3.4: 1$ men to every woman in another multicenter survey over a 3-year study period. This sex distribution can be attributed to high prevalence of risk factors like smoking, DM, $\mathrm{HCV}$, and industrial exposure to aflatoxins in males in addition to possible role of sex hormones.

In Egypt, the limited resources and increased burden of high number and growing incidence of $\mathrm{HCC}$ cases creates a big problem of how to deal with this gush of cases specially after mass treatment of chronic $\mathrm{HCV}$ with direct acting antiviral (DAAs). In our study, we found statistically significant association of $\mathrm{HCC}$ with previous anti-HCV treatment with DAAs $(72.3 \%$ of cases) in comparison to the other two groups with $P=0.01$ (Table 2) suggesting the role of DAAs in HCC development. This runs parallel to recent

Table 6 Sensitivity and specificity of $\alpha$-fetoprotein in differentiating hepatocellular carcinoma cases

\begin{tabular}{|c|c|c|c|c|c|c|c|}
\hline & AUC & Cut-off point & Sensitivity (\%) & Specificity (\%) & Positive predictive value (\%) & Negative predictive value (\%) & Accuracy (\%) \\
\hline AFP & 0.83 & $\geq 11.2$ & 81.1 & 71.9 & 81.6 & 71.1 & 77.5 \\
\hline
\end{tabular}

AFP, $\alpha$-fetoprotein; AUC, area under the curve. 
Table 7 Binary logistic regression for prediction of hepatocellular carcinoma cases

\begin{tabular}{|c|c|c|c|}
\hline Predictors & $?$ & $P$ & Odds ratio $(95 \% \mathrm{Cl})$ \\
\hline \multicolumn{4}{|l|}{ Age (years) } \\
\hline 58 & 1.5 & $<0.001^{\star}$ & 1 \\
\hline$>58$ & & & $4.5(2.3-8.8)$ \\
\hline Sex (male) & -1.41 & $0.004^{*}$ & $0.24(0.09-0.64)$ \\
\hline \multicolumn{4}{|l|}{ Occupation } \\
\hline Not working (r) & -0.07 & 0.86 & 1 \\
\hline Manual worker & 2.09 & 0.06 & $0.9(0.4-2.1)$ \\
\hline Employee & 0.53 & 0.34 & $8.1(0.91-72.02)$ \\
\hline Healthcare worker & & & $1.69(0.57-5.08)$ \\
\hline Diabetes & 0.34 & 0.37 & $1.4(0.66-2.95)$ \\
\hline \multicolumn{4}{|l|}{ Antibilharial treatment } \\
\hline No & 0.16 & 0.69 & 1 \\
\hline Oral & 0.68 & 0.15 & $1.17(0.54-2.55)$ \\
\hline Injection & & & $1.98(0.78-4.9)$ \\
\hline $\mathrm{Hb}$ & -0.064 & 0.546 & $0.93(0.7-1.2)$ \\
\hline WBCs & 0.000 & 0.594 & $1.0(1.0-1.0)$ \\
\hline PLT & 0.000 & 0.060 & $1.0(1.0-1.0)$ \\
\hline ALT & 0.001 & 0.890 & $1.01(0.99-1.02)$ \\
\hline AST & 0.001 & 0.924 & $1.01(0.98-1.02)$ \\
\hline Albumin & -0.718 & $0.035^{\star}$ & $0.49(0.25-0.95)$ \\
\hline INR & -0.245 & 0.803 & $0.78(0.11-5.4)$ \\
\hline \multicolumn{4}{|l|}{ AFP } \\
\hline$<11.2(r)$ & 2.24 & $<0.001^{\star}$ & 1 \\
\hline$>11.2$ & & & $9.4(4.65-19.1)$ \\
\hline Bilirubin & -0.083 & 0.522 & $0.92(0.71-1.19)$ \\
\hline
\end{tabular}

Percentage predicted $=76.3 \%$. Model $\chi^{2}=106.3 .9$. AFP, $\alpha$-fetoprotein; $\mathrm{ALT}$, alanine aminotransferase; AST, aspartate aminotransferase; $\mathrm{Cl}$, confidence interval; $\mathrm{Hb}$, hemoglobin; INR, international normalized ratio; PLT, platelets; WBC, white blood cells. ${ }^{*} P$ value is significant.

reports from Europe that showed sustained recurrence of $\mathrm{HCC}$ in the short term follow up after treatment with DAAs, which has been hypothesized to be due to the rapid decline in HCV load brings about a misbalance of $\mathrm{HCV}$ stimulated immune control that allows tumor clones to emerge $[11,12]$. In contrast, other studies do not support this finding [13-15]. This disagreement may be related to the difference in study design or treatment options to which those patients were exposed.

On analyzing laboratory characters of the studied groups, we found statistically significant association of HCC with high AST, thrombocytopenia, hypoalbuminaemia, increased bilirubin, and prolonged prothrombin time with $P$ less than 0.001 for all parameters (Table 3 ). These findings seem logical because HCC often develop in a background of chronic liver disease and these parameters are used to stage chronic liver disease either through Child-Turcotte-Pugh score or model for end stage liver disease score. This runs parallel to El-Serag [16] and Forner et al. [17], who concluded that cirrhosis, which is the most important risk factor for $\mathrm{HCC}$ is present in $80-90 \%$ patients with HCC. The accumulated risk at 5 years for the development of $\mathrm{HCC}$ in cirrhotic patients ranges from 5 to $30 \%$ depending on the etiology of cirrhosis, ethnic group, region, and the stage of cirrhosis. The risk of HCC increases in patients with uncontrolled liver cirrhosis [18].

In our study, the statistically significant association of HCC with high AST in comparison to the other two groups has an important significance that $\mathrm{HCC}$ is usually associated with marked degree of fibrosis as AST is incorporated in almost all fibrosis scoring systems like AST-platelet ratio index, FIB-4 index, and Forns index and hence, when AST increase logically these scores will also increase and hence reflect marked degree of fibrosis. This is in agreement with Toyoda et al. [19] who concluded that Forns index, especially when assessed before anti-HCV therapy is a useful laboratory liver fibrosis index for identifying patients less likely to develop HCC after sustained virologic response. Furthermore, this index can be used as one of indicators to consider the termination of surveillance for HCC after the eradication of HCV [19].

In our study, we evaluated the validity of US and CT scanning and AFP in diagnosis of HCC. We found that US has sensitivity of $85.2 \%$ and specificity of 92.6\% with $88.4 \%$ accuracy whereas CT scanning has sensitivity of $99.3 \%$ and specificity of $83.9 \%$ with $96.6 \%$ accuracy (Table 5).

US is the most common available imaging technique used for evaluation of abdominal organs as it is noninvasive and relative low in cost. The accuracy of detection of HCC by US varies largely and in patients with cirrhosis, its sensitivity is about 33-96\% [20] with specificity reaching over 90\% [21]. Detection of small $\mathrm{HCC}$ foci in cirrhotic liver may present as a challenge, especially in presence of regenerative nodules. Therefore, it is of great importance, that US should be performed by expert and well-qualified personnel using optimal equipment, preferably in dedicated centers. In comparison to conventional gray-scale US, CEUS provides higher diagnostic efficacy in differentiation of benign and malignant focal liver lesions, often comparable to that achieved in MRI [22]. In addition, US sensitivity decrease with small lesions less than $2 \mathrm{~cm}$ and this is what drives Hennedige and Venkatesh [23] to recommend triphasic CT scan or MRI to evaluate lesions less than $2 \mathrm{~cm}$ in high-risk cirrhotic patients to rule out $\mathrm{HCC}$.

Observational cohort and case control studies have demonstrated that the patients benefit from surveillance. The expected benefit come from the fact that patients diagnosed early are candidate for 
better treatment options like resection or liver transplantation. This motivated some but not all professional societies, such as American Association for the study of Liver diseases to recommend surveillance for patients at high risk of HCC [24]. The AFP is the commonest tumor marker used for this purpose. However, its sensitivity ranges from about $25 \%$ for lesions smaller than $3 \mathrm{~cm}$ to $50 \%$ for tumors more than $3 \mathrm{~cm}$ in diameter [25]. In the current study, we found that AFP has a sensitivity of $81.1 \%$ and a specificity of $71.9 \%$ with $11.2 \mathrm{ng} / \mathrm{dl}$ cut-off values (Fig. 2 and Table 6). Trevisani et al. [26], Marrero et al. [27] and Lok et al. [28] investigated the accuracy of AFP as a serum biomarker for early detection of HCC with cut-off values between 10 and $20 \mathrm{ng} / \mathrm{dl}$, they found its diagnostic sensitivity is about $60 \%$. This difference may be related to differences in size of tumors, etiology of cirrhosis, or method of AFP assay.

EASL recommend screening and follow up of cirrhotic patients with Child-Pugh A, B and C, and who are awaiting liver transplants, patients presenting with chronic hepatitis C, and advanced liver fibrosis. Screening should include those receiving antiviral therapy, especially for chronic hepatitis C patients who have developed cirrhosis, regardless of sustained virologic response during or after termination of the course of treatment [29].

The purpose of screening of patients at high risk is to reduce mortality by early detection and implementation of effective therapy. This purpose is achieved when we catch single foci smaller than $2 \mathrm{~cm}$ in diameter, which exhibits a better prognosis and less than $20 \%$ risk of hematogenous spread [30].

In our study, we tried to detect patients with liver cirrhosis who are at highest risk to develop HCC by binary logistic regression for prediction of $\mathrm{HCC}$ cases, we found that male patients aged more than $58 \mathrm{y}$ with hypoalbuminaemia and AFP greater than $11.2 \mathrm{ng} / \mathrm{dl}$ are at a higher risk to develop HCC more than other patients with $76.3 \%$ predicted (Table 7 ). This appears logical because advanced age and being a male are standard risk factors for majority of cancers, where hypoalbuminaemia reflects the presence of advanced liver disease, which is widely accepted as the most important risk factor for HCC [31]. Our findings support this, where hypoalbuminaemia is more pronounced with advancing stage of HCC (Table 4). Finally, we can assume that we should screen liver cirrhosis in male patients aged more than 58 years with hypoalbuminaemia and AFP greater than $11.2 \mathrm{ng} / \mathrm{dl}$ at closer periods and better with contrast-enhanced technique.

\section{Conclusion}

We concluded that, screening patients with liver cirrhosis who are males aged more than 58 years with hypoalbuminaemia and AFP greater than $11.2 \mathrm{ng} / \mathrm{dl}$ for HCC should be monitored at close quarters with contrast-enhanced technique either CEUS or CT scan.

\section{Financial support and sponsorship}

Nil.

\section{Conflicts of interest}

There are no conflicts of interest.

\section{References}

1 Hemming AW, Berumen J, Mekeel K. Hepatitis B and hepatocellular carcinoma. Clin Liver Dis 2016; 20:703-720.

2 Seydel GS, Kucukoglu O, Altinbas A, Demir OO, Yilmaz S, Akkiz H, et al. Economic growth leads to increase of obesity and associated hepatocellular carcinoma in developing countries. Ann Hepatol 2016; 15:5.

3 El-Serag HB. Epidemiology of hepatocellular carcinoma. Clin Liver Dis 2001; 5:87-107.

4 Luo J-C., Hwang S-J., Wu J-C., Li C-P., Hsiao L-T., Lai C-R., et al. Paraneoplastic syndromes in patients with hepatocellular carcinoma in Taiwan. Cancer 1999; 86:799-804.

5 Ghanaati H, Alavian SM, Jafarian A, Daryani NE, Nassiri-Toosi M, Jalali $\mathrm{AH}$, Shakiba M. Imaging and imaging-guided interventions in the diagnosis and management of hepatocellular carcinoma (HCC)-review of evidence. Iran J Radiol 2012; 9:167-177.

6 Stefaniuk P. Present and future possibilities for early diagnosis of hepatocellular carcinoma. World J Gastroenterol 2010; 16:418.

7 Varela M, Reig M, Mata MD, Matilla A, Bustamante J, Pascual S, et al. Tratamiento del carcinoma hepatocelular en España. Análisis de 705 casos en 62 centros. Med Clín 2010; 134:569-576.

8 Carrilho FJ, Kikuchi L, Branco F, Goncalves CS, Mattos AAd. Clinical and epidemiological aspects of hepatocellular carcinoma in Brazil. Clinics 2010; 65:1285-1290.

9 Alves R, Harriz M, Vanini H, Alves D, Soares S, Montalveme T, et al. Carcinoma Hepatocelular: Aspectos Epidemiológicos em 210 Casos. Rev Assoc Med Rio Grande Do Sul 2009; 53(S3): S43.

10 GonÇAlves CS, Pereira FEL, Gayotto LCC. Hepatocellular carcinoma in Brazil: report of a national survey (Florianópolis, SC, 1995). Rev Inst Med Trop São Paulo 1997; 39:165-170.

11 Reig $M$, Mariño Z, Perelló C, Iñarrairaegui $M$, Ribeiro A, Lens $S$, et al. Unexpected high rate of early tumor recurrence in patients with HCV-related HCC undergoing interferon-free therapy. J Hepatol 2016; 65:719-726.

12 Conti F, Buonfiglioli F, Scuteri A, Crespi C, Bolondi L, Caraceni P, et al. Early occurrence and recurrence of hepatocellular carcinoma in HCVrelated cirrhosis treated with direct-acting antivirals. J Hepatol 2016; 65:727-733.

13 Meissner EG, Kohli A, Virtaneva K, Sturdevant D, Martens C, Porcella SF, et al. Achieving sustained virologic response after interferon-free hepatitis $C$ virus treatment correlates with hepatic interferon gene expression changes independent of cirrhosis. J Viral Hepat 2016; 23:496-505.

14 Cabibbo G, Petta S, Calvaruso V, Cacciola I, Cannavò MR, Madonia S, et al. Is early recurrence of hepatocellular carcinoma in HCV cirrhotic patients affected by treatment with direct-acting antivirals? A prospective multicentre study. Aliment Pharmacol Ther 2017; 46:688-695.

15 Kanwal F, Kramer J, Asch SM, Chayanupatkul M, Cao Y, El-Serag HB. Risk of hepatocellular cancer in HCV patients treated with direct acting antiviral agents. Gastroenterology 2017; 153:996-1005 
16 El-Serag HB. Epidemiology of viral hepatitis and hepatocellular carcinoma. Gastroenterology 2012; 142:1264-1273.e1261.

17 Forner A, Llovet JM, Bruix J. Hepatocellular carcinoma. Lancet 2012; 379:1245-1255.

18 Fattovich G, Stroffolini T, Zagni I, Donato F. Hepatocellular carcinoma in cirrhosis: Incidence and risk factors. Gastroenterology 2004; 127:S35-S50.

19 Toyoda H, Tada T, Tachi Y, Hirai T, Yasuda S, Honda T, et al. Liver fibrosis indices for identifying patients at low risk of developing hepatocellular carcinoma after eradication of HCV. Antivir Ther 2016; 22:185-193.

20 Bennett GL, Krinsky GA, Abitbol RJ, Kim SY, Theise ND, Teperman LW. Sonographic detection of hepatocellular carcinoma and dysplastic nodules in cirrhosis: correlation of pretransplantation sonography and liver explant pathology in 200 patients. Am J Roentgenol 2002; 179:75-80.

21 Bolondi L. Screening for hepatocellular carcinoma in cirrhosis. J Hepatol 2003; 39:1076-1084.

22 Claudon M, Dietrich CF, Choi BI, Cosgrove DO, Kudo M, Nolsøe CP, et al. Guidelines and good clinical practice recommendations for contrast enhanced ultrasound (CEUS) in the liver-update 2012: a WFUMBEFSUMB initiative in cooperation with representatives of AFSUMB, AIUM, ASUM, FLAUS and ICUS. Ultrasound Med Biol 2013; 39:187-210.

23 Hennedige T, Venkatesh SK. Imaging of hepatocellular carcinoma: diagnosis, staging and treatment monitoring. Cancer Imaging 2012; 12:530-547.
24 Zhang B-H, Yang B-H, Tang Z-Y. Randomized controlled trial of screening for hepatocellular carcinoma. J Cancer Res Clin Oncol 2004; 130:7.

25 Ho C, Chen S, Yeung DWC, Cheng TKC. Dual-tracer PET/CT imaging in evaluation of metastatic hepatocellular carcinoma. J Nucl Med 2007; 48:902-909.

26 Trevisani F, D'Intino PE, Morselli-Labate AM, Mazzella G, Accogli E, Caraceni $P$, et al. Serum $\alpha$-fetoprotein for diagnosis of hepatocellular carcinoma in patients with chronic liver disease: influence of HBsAg and anti-HCV status. J Hepatol 2001; 34:570-575.

27 Marrero JA, Feng Z, Wang Y, Nguyen MH, Befeler AS, Roberts LR, et al. $\alpha$-Fetoprotein, des- $\gamma$ carboxyprothrombin, and lectin-bound $\alpha$-fetoprotein in early hepatocellular carcinoma. Gastroenterology 2009; 137:110-118.

28 Lok AS, Sterling RK, Everhart JE, Wright EC, Hoefs JC, Di Bisceglie AM, et al. Des- $\gamma$-carboxy prothrombin and $\alpha$-fetoprotein as biomarkers for the early detection of hepatocellular carcinoma. Gastroenterology 2010; 138:493-502.

29 EASL-EORTC Clinical Practice Guidelines. Management of hepatocellular carcinoma. J Hepatol 2012; 56:908-943.

30 Roskams T. Anatomic pathology of hepatocellular carcinoma: impact on prognosis and response to therapy. Clin Liver Dis 2011; 15:245-259.

31 Herbst DA, Reddy KR. Risk factors for hepatocellular carcinoma. Clin Liver Dis $2012 ; 1: 180-182$. 